\title{
Elliptical and Circular Bonded Composite Repair under Mechanical and Thermal Loading in Aircraft Structures
}

\author{
Faycal Benyahia ${ }^{a}$, Abdulmohsen Albedah ${ }^{a}$, Bel Abbes Bachir Bouiadjra ${ }^{b *}$ \\ ${ }^{a}$ Mechanical Engineering Department, College of Engineering, King Saud University, \\ Riyadh, Saudi Arabia \\ ${ }^{b}$ LMPM, Department of Mechanical Engineering, University of Sidi Bel Abbes, BP 89, \\ Cité Ben M'hidi, Sidi Bel Abbes, Algeria
}

Received: December 24, 2013; Revised: October 5, 2014

\begin{abstract}
In this study, the three-dimensional finite element method is used to achieve a comparison between the semi circular and semi elliptical patch repairs in aircraft structures. The comparison was done by the analysis of : the mechanical and thermal stress intensity factors (SIF and TSIF) at the tip of repaired crack and the distribution of the adhesive stresses for the two patch shapes. The obtained results show that the semi circular shape of the patch presents lower stress intensity factor at the crack tip, which is beneficial for the fatigue life and lower adhesives stresses, which is beneficial for the repair durability. In addition the circular patch is subjected to less significant thermal residual stresses compared to the elliptical shapes.
\end{abstract}

Keywords: bonded composite repair, adhesive, thermal stresses, stress intensity factor, finite element method

\section{Introduction}

Recently, the use of adhesives is accepted as a process of structures repairs to increase the service life of damaged components ${ }^{1-6}$. The metal or composite patches are stuck on a single or on both faces of the cracked structural components. The repair of the cracks by gluing composite material patches proved its efficiency by reducing the stress intensity at the cracks tips. This method has been successfully used in repairing damaged plane components. Considerable work has been done to develop the technique of fitting the composite patches on aeronautical structures ${ }^{7-9}$.

With the increase in computational power, the use of the numerical method, especially the finite elements method, contributed considerably to the comprehension of the mechanical behavior of defects under patch repair. The finite element method has been used for the study of the crack patching by many authors, we can quote: Callinan et al. ${ }^{8}$, Jones and Chiu ${ }^{9}$, Chung and Yang ${ }^{10}$ and Bachir Bouiadjra et al. ${ }^{11}$ Many researchers have studied crack reinforcement of stiffeners or pre-stresses on the stress intensity factor at the cracks tip or notches by the optical method of caustics ${ }^{12,13}$. Papadopoulos and Konsta-Gdoutos ${ }^{14}$ indicated that this method is simple in its application and has successfully been used for the solution of a host of crack problems of engineering importance. The adhesive properties thus play an important role on the performances of the bonded composite repair. Bachir Bouiadjra et al. ${ }^{15}$ showed that an adhesive with high shear modulus (with bad qualities) gives weak stress intensity factor at repaired crack tips. They are thus recommended for increasing the performance of bonded composite repair in spite of the fact

*e-mail: bachirbou@yahoo.fr that higher adhesive shear modulus leads to higher adhesive stresses, which increases the risk of adhesive failure. They concluded that the adhesive properties must be optimised in order to improve the performance of the repair and to avoid the adhesive failure ${ }^{15}$.

A good way to design a patch repair can be the determination of the optimal shape in order to obtain the maximum safety-cost ratio ${ }^{15}$. Such a problem is very important nowadays from both economic and technical point of views ${ }^{16-18}$, in a wide range of engineering fields, especially in aeronautical applications. The analysis of the effects of the geometrical properties of the composite on the repair performance got great interest in the literature. Heller and Kaye ${ }^{19}$ used the genetic algorithm to optimize the patch shape. Kaddouri et al. ${ }^{20}$, Ouinas et al..$^{21,22}$ analyzed numerically the performance of the octagonal, circular and elliptical shapes of the patches. They showed that the patch shape has a significant effect on the value of the stress intensity factor at the crack tip. In addition, the use of appropriate patch shapes can reduce the level of the thermal residual stresses due to the adhesive curing.

Bonded composite patch repair involves firstly heating the local area being patched above the ambient temperature, and subsequently cooling the fully cured patch, which can be regarded as rigidly bonded to the structure, to the ambient temperature ${ }^{23}$. For instance, in a typical repair applied to aircraft structures the reinforced region is initially heated to a temperature of approximately $100-120^{\circ} \mathrm{C}$, under pressure, for approximately one hour and then cooled down to the ambient temperature after the adhesive is cured ${ }^{24}$. Due to the differences between the elastic properties and the 
thermal expansion properties of the composite patch and the metalllic plate, thermal residual stresses may arise. It has long been recognized that in some cases the thermal residual stresses represent a serious concern to the repair efficiency of composite patch repair ${ }^{25}$. If the repair material is different to the substrate, the level of residual stress should be calculated during the design process. Attempts to estimate the values of residual stress have been many in recent years. Aminallah et al. ${ }^{24}$ used the finite element method to estimate the intensities of the thermal stresses in bonded composite repair of aircraft structures, they concluded that The thermal normal stresses are relatively important in the patch and the plate. The patch is subjected to compressive stress filed and the plate to tensile one. Albedah et al. ${ }^{26}$ analyzed the effects of the thermal stresses on the stress intensity factor (SIF) variation in aluminum plate repaired with Boron/epoxy patch. The two structures are bonded with FM 73 epoxy adhesive film. These authors showed that the aluminum plate exerts compressive stresses on the composite patch, This is because the thermal coefficient of expansion of the aluminum is greater than that of boron/epoxy. According to Albedah et al. ${ }^{26}$, the thermal residual stresses lead to an increase of the SIF, which provoke the reduction of the fatigue life of repaired aeronautical structures. To attenuate the effects of the thermal residual stresses on the repair performance, the curing temperature and the adhesive properties must be optimized. Mhamdia et al. ${ }^{27}$ analyzed the variation of the stress intensity factor at tip of repaired crack under thermo-mechanical loading, they concluded that the negative effect of the thermal residual stresses can be minimized if the adhesive properties are optimized and if the patch height is reduced.

In the present paper, the finite element method was used to compare the repair performances between semi circular and semi elliptical shapes of the patch. This comparison is made by the computation of the mechanical and thermal stress intensity factor (SIF) at the crack tip and the adhesive stresses for both shapes of the composite patch repair.

\section{Geometrical and Materials Models}

Consider a thin elastic aluminium plate with the following dimensions: height $H_{p}=203 \mathrm{~mm}$, width $W_{p}=76.2 \mathrm{~mm}$ and thickness $\mathrm{e}_{\mathrm{p}}=2 \mathrm{~mm}$. An edge crack of length a is supposed to initiate in the aluminium plate. The crack is repaired with semi circular and semi elliptical bonded composite patch repair of boron / epoxy with the following dimensions (Figure 1):

- Semi circular patch : radius $\mathrm{R}=76.2 \mathrm{~mm}$ ( The radius is equal to the plate width) and the patch thickness is $\mathrm{e}_{\mathrm{r}}=1 \mathrm{~mm}$

- Semi-elliptical patch: with great base $b=76.2 \mathrm{~mm}$ (The great base is equal to the plate width) and little base $\mathrm{c}$ (Figure 1). The ratio $\mathrm{c} / \mathrm{R}$ was varied in order to analyse its effect on the repair performances. The patch thickness is fixed to $\mathrm{e}_{\mathrm{r}}=1 \mathrm{~mm}$. The composite patch is bonded to the cracked plate with the FM 73 adhesive having a thickness of : $e_{a}=0.127 \mathrm{~mm}$.

The plate is subjected to a remote uni-axial tensile stress on the vertical direction (y) with an amplitude of
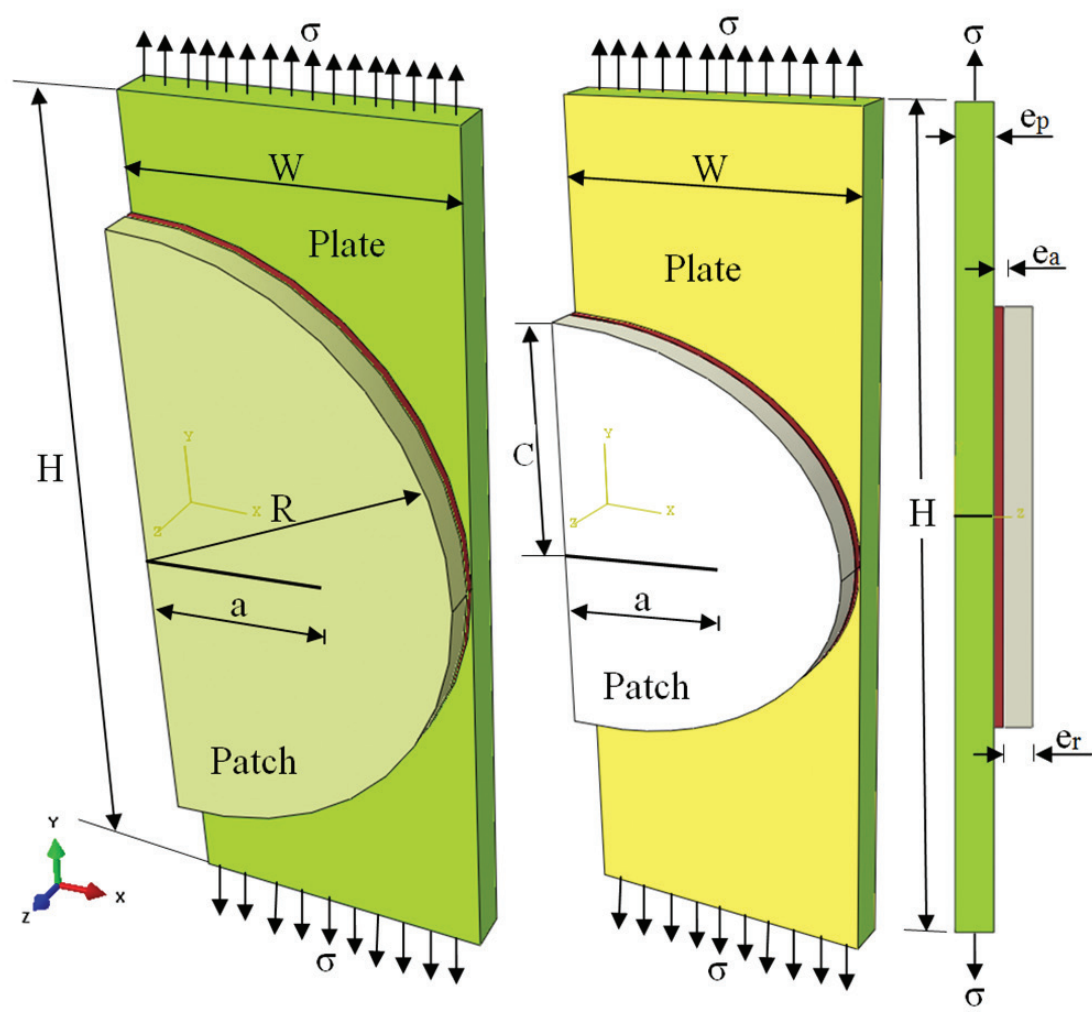

Figure 1. Geometrical model. 
$\sigma=120 \mathrm{MPa}$. Since the geometry and loading are symmetric, it is sufficient to analyze only the half of the structure. It is assumed that the different materials (aluminium, composite and adhesive) have an elastic behaviour. The aluminium and the adhesive are analysed as isotropic materials and the Boron/epoxy is considered as orthotropic material. The elastic properties of the plate, patch and adhesive are given in Table 1.

\section{Finite Element Model}

The analysis involved a three-dimensional finite element method by using the commercially available finite element code ABAQUS ${ }^{28}$. The finite element model consists of three subsections to model the cracked plate, the adhesive, and the composite patch. Due to loading symmetry, only the half of the repaired plate was considered. The plate had four layers of elements in the thickness direction, the adhesive had only one layer of elements through thickness and the patch had two layers of elements through thickness. To generate crack front some brick elements are replaced by « crack block ». These crack- block are meshes of brick elements which are mapped into the original element space and merged with surrounding mesh. Boundary conditions and loads are transferred to the crack-block elements. The mesh was

Table 1. Materials properties (plate, patch and adhesive).

\begin{tabular}{lccc}
\hline \multicolumn{1}{c}{ Property } & Aluminium & Boron/epoxy & Adhesive \\
\hline$E_{1}(G P a)$ & 72 & 208 & \\
$E_{2}(G P a)$ & & 25.4 & \\
$v_{12}$ & 0.33 & 0.1677 & 0.32 \\
$E_{12}(G P a)$ & & 7.2 & 0.965 \\
$E_{13}(G P a)$ & & 7.2 & \\
$\alpha\left(10^{-6}{ }^{\circ} \mathrm{C}^{-1}\right)$ & 22.7 & 4.5 & 50.0 \\
\hline
\end{tabular}

refined near the crack tip area with an element dimension of $0.067 \mathrm{~mm}$ using at least fifteen such fine elements in the front and back of the crack tip. The finite element mesh was generated using brick elements with 20 nodes. The number of element used in this analysis is 49351 and number of degrees of freedom DOF is: 322016 . Figure 2 shows the overall mesh of the specimen and mesh refinement in the crack tip region. The Stress intensity factor at the crack front was computed using the virtual crack closure technique (VCCT). This technique was originally proposed in 1977 by Rybicki and Kanninen ${ }^{29}$ for bidimensionnel cases. The VCCT is a very attractive SIF extraction technique because of its good accuracy, a relatively easy algorithm of application capability to calculate the SIF for all three fracture modes. Other authors ${ }^{30}$ have extended the proposed technique. Currently, the three-dimensional virtual crack closure technique (3D VCCT) is often chosen as a tool for SIF calculations ${ }^{31}$.

The VCCT is based on the energy balance proposed by Irwin. In this technique, SIF are obtained for three fracture modes from the equation:

$G_{i}=\frac{K_{i}^{2}}{E}$

Where $G_{i}$ is the energy release rate for mode $i, K_{i}$ the stress intensity factor for mode $i, E$ the Young modulus of the material

\section{Results and Discussion}

\subsection{Mechanical loading}

\subsubsection{Computation of the stress intensity factor}

In this section, the variation of the stress intensity factor at the crack tip is computed for semi-circular shape of the patch and for semi-elliptical shape with different ratio

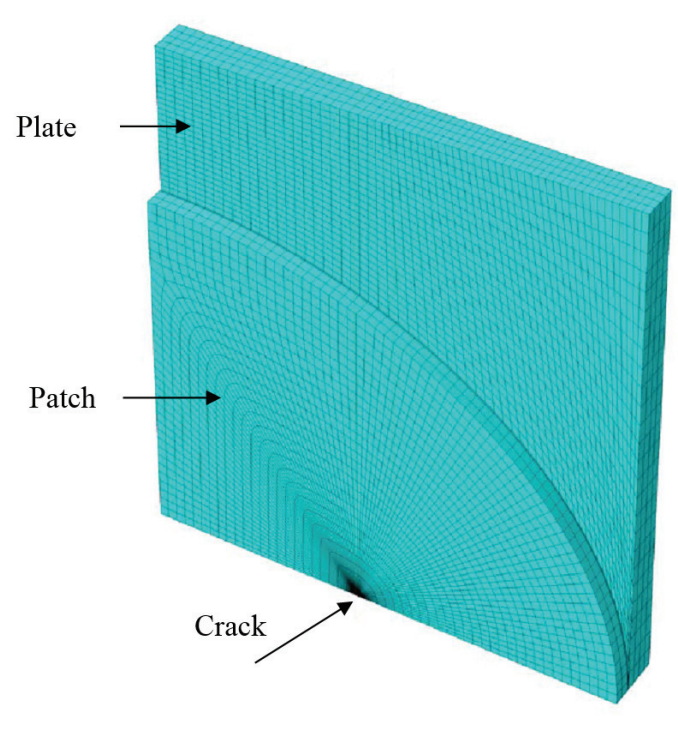

(a)

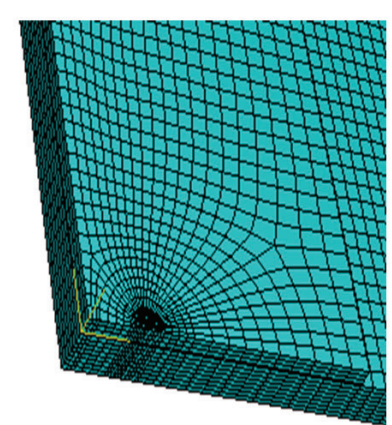

(b)

Figure 2. Typical mesh model. a) Of the half of the structures. b) Near the crack front. 
$\mathrm{c} / \mathrm{b}$. Figure 3 shows the variation of the stress intensity factor according to the crack length for semi-circular patch $(\mathrm{c} / \mathrm{R}=1)$ and semi-elliptical one with various ratio $\mathrm{c} / \mathrm{R}(\mathrm{c} /$ $\mathrm{R}=0.5,0.66$ and 0.86 ). One can note, according to the results of Figure 3, that the stress intensity factor exhibits an asymptotic behaviour whatever the shape and the size of the composite patch. This is because the patch carries the loads as the crack grows. Several investigators announced this tendency ${ }^{6,11,20,22}$. It can also noted, according to the results of Figure 3 that the semi-circular shape of patch presents lower values of the stress intensity factor at the crack tip. The semi-circular patch can thus increase the fatigue life of repaired aircraft structures compared to the elliptical shape. The difference in the stress intensity factor between the circular and the elliptical shapes increases when the crack length increases. This is because for long cracks the stress intensity at the crack tip is significant enough to permit higher stress transfer between the repaired plate and the composite patch throughout the adhesive layer. According to the ratio $\mathrm{c} / \mathrm{R}$, one can note that the difference in the SIF between the semi-circular and semi-elliptical patch shapes increases with the increase of the ratio $\mathrm{c} / \mathrm{R}$. For example for crack length $\mathrm{a}=10 \mathrm{~mm}$, the value of the SIF for semi-circular patch is $9.45 \mathrm{MPa}(\mathrm{m})^{1 / 2}$ and the SIF value is $11.43 \mathrm{MPa}$ $(\mathrm{m})^{1 / 2}$ for semi-elliptical patch with $\mathrm{c} / \mathrm{R}=0.5$, the relative difference is about $17 \%$. For $\mathrm{a}=27.5 \mathrm{~mm}$, the value of the SIF is about $11.16 \mathrm{MPa}(\mathrm{m})^{1 / 2}$ for semi-circular patch and this value is about $13.76 \mathrm{MPa}(\mathrm{m})^{1 / 2}$ for semi-elliptical patch with $\mathrm{c} / \mathrm{R}=0.5$. The relative difference in this case is about $19 \%$.

In order to confirm the precedent results, Figure 4 presents the variation of the stress intensity factor according to the ratio $\mathrm{c} / \mathrm{R}$ for different crack lengths. It can be seen that for small crack length, $(\mathrm{a}=5 \mathrm{~mm})$ the effect of the ratio $\mathrm{c} / \mathrm{R}$ on the SIF variation is less significant. The relative variation in the SIF between the cases $\mathrm{c} / \mathrm{R}=1$ (circular shape) and $\mathrm{c} /$ $\mathrm{R}=0.5$ is about $17 \%$. This difference slightly increases to $23 \%$ when the crack length is equal to $45 \mathrm{~mm}$.

One can conclude that the gain in the stress intensity factor and consequently the gain in the repair efficiency by the use of circular patch shape increases if the ratio $c / R$ decreases but this gain slightly grows with the increases of the crack size.

\subsubsection{Computation of the adhesive shear stresses}

In this section, the adhesive shear stresses are computed for the two patch shapes (semi-circular and elliptical) in order to estimate the repair durability. Figure 5 presents the distribution of the adhesive shear stresses $\left(\tau_{\mathrm{xz}}\right)$ in the $\mathrm{xz}$ plane along the adhesive layer for semi circular and semielliptical patch shapes. One can see that the adhesive stresses in this plane are weak and the risk of adhesive failure due to the adhesive shear stresses $\tau_{\mathrm{xz}}$ is very weak. Indeed, the maximal shear stresses are registered for the semi-elliptical with $\mathrm{c} / \mathrm{R}=0.83$ and the maximal stresses is about $2.5 \mathrm{MPa}$ in absolute value. This value is ten time less to the adhesive strength (about $30 \mathrm{MPa}$ for the FM Epoxy adhesive). The weak values of the adhesive stresses in the (xz) plane can be explained by the fact that the applied load is parallel to the $y$ axis, which generates weak stresses in the (xz) plane.

Figure 6 presents the distribution of the adhesive stresses along the adhesive layer in the (yz) plane. It can be

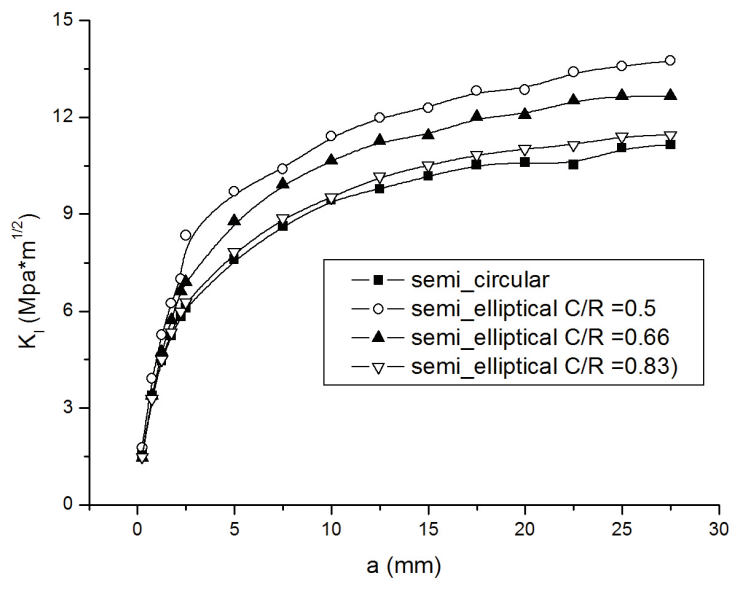

Figure 3. Variation of the SIF according to the crack length for different ratio $\mathrm{c} / \mathrm{R}$.

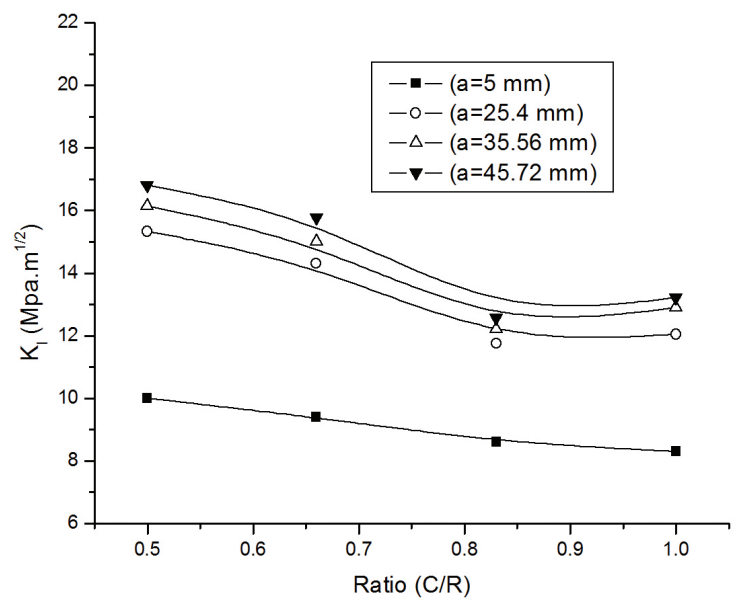

Figure 4. Variation of the SIF according to the ratio $\mathrm{c} / \mathrm{R}$ for different crack length.

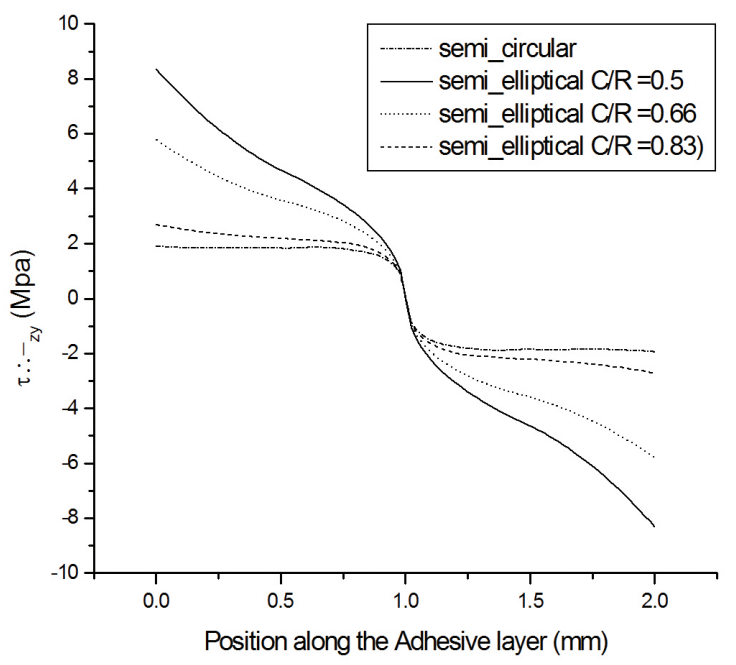

Figure 5. Distribution of the adhesive shear stresses $\tau_{\mathrm{zx}}$ 
noted, that the level of the adhesive stresses in this plane are relatively important. The maximal stresses are recorded for the semi-elliptical shape of the patch with $\mathrm{c} / \mathrm{R}=0.5$. The maximal value is about $9 \mathrm{MPa}$, the risk of adhesive failure is thus more important in this plane. It can be also noted that the semi-circular shape of the patch presents lower level of the adhesive shear stresses. The risk of adhesive failure is less important for this patch shape. The repair durability can be improved by the use of semi-circular patches. The analysis of the effect of the ratio $\mathrm{c} / \mathrm{R}$ on the levels of the adhesive stresses shows that the increase of this ratio decreases the intensity of the adhesive stresses. The use of semi-elliptical patches with higher ratio $\mathrm{c} / \mathrm{R}$ allows the improvement of the repair durability.

\subsubsection{Estimation of the mass gain}

For a better analysing the advantages semi-circular patch, we tried to estimate numerically the mass gain resulting from the use of semi-circular patches compared to semi-elliptical patches. The mass gain is defined as the ratio between the volume of the semi-circular and semielliptical patches giving the same stress intensity factor at the crack tip:

$$
\operatorname{Gain}(\%)=\frac{V_{s c}}{V_{s e}} \times 100
$$

Where $\mathrm{V}_{\mathrm{sc}}$ is the volume of the semi-circular patch and $\mathrm{V}_{\mathrm{se}}$ is the volume of the semi-elliptical patch.

Figure 7 presents the variation of the mass gain as a function of the ratio $\mathrm{c} / \mathrm{R}$. It can be seen that the mass gain can be very significant. Indeed, then value of this gain is about $50 \%$ when the ratio $\mathrm{c} / \mathrm{R}=0.5$. This means that the repair cost can be improved with $50 \%$ by using semi-circular patch instead of semi-elliptical patch with $\mathrm{c} / \mathrm{R}=0.5$. The mass gain and the repair cost decreases when the ratio $\mathrm{c} / \mathrm{R}$ increases.

\subsection{Thermal loading}

In this section, the thermal stresses (TSIF) are computed for two patch shapes. The coefficients of the thermal expansions are:

- For the aluminum $\alpha=22.310^{-6}{ }^{\circ} \mathrm{C}^{-1}$

- For the carbon/epoxy: Longitudinal coefficient $=2.1$ $10^{-6}{ }^{\circ} \mathrm{C}^{-1}$, Transversal coefficient $=2.110^{-6}{ }^{\circ} \mathrm{C}^{-1}$.

Figure 8 presents the variation of the maximal thermal stresses in the plate and the composite patches as a function of the ratio $\mathrm{c} / \mathrm{R}$ defined previously for comparison between circular and elliptical patches. The stresses are calculated in the fibre direction (parallel to the direction of the applied load). We can see the process of adhesive curing involves relatively high level of thermal stresses along the fibre axis in the plate and the sign of this stresses is positive. It means that, according to the fibre direction, the aluminum plate is under tensile stresses. This is due to the fact that during the cooling the composite patch prevents the return of the aluminum plate to its initial position after dilatation. This behavior leaves the plate in tension.

The stresses in the patch are negative, this means that the patch is in compression. The compressive stresses are exerted by the plate. The stresses intensity in the patch is less significant compared to the stress field in the plate. This is due to the fact that the thermal coefficient of expansion for aluminum is greater than that of boron/epoxy. However, the stresses in the composite are relatively significant because there is a transfer of stresses from the aluminum plate to the composite patch throughout the adhesive layer. On the other hand, we can see from Figure 8 that the circular patch shape involves more significant values of the thermal

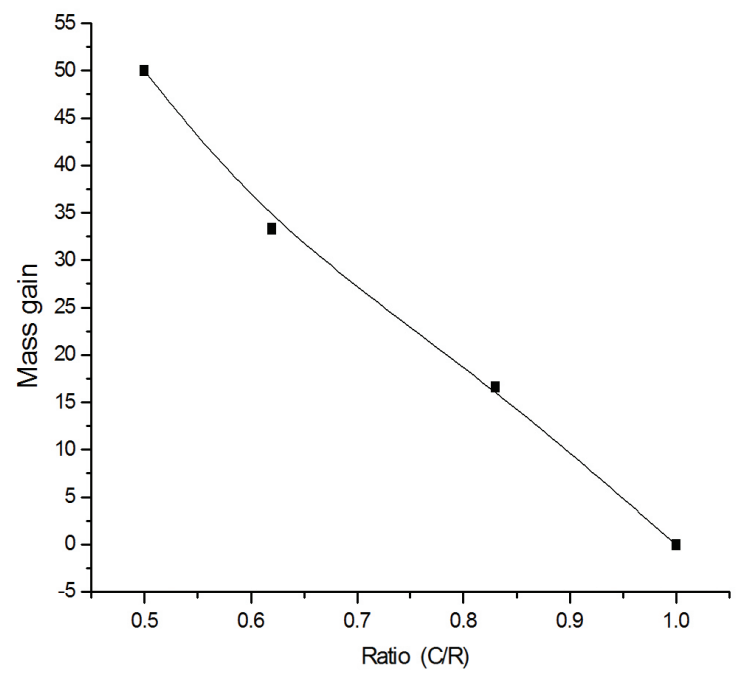

Figure 6. Distribution of the adhesive shear stresses $\tau_{\mathrm{yz}}$.

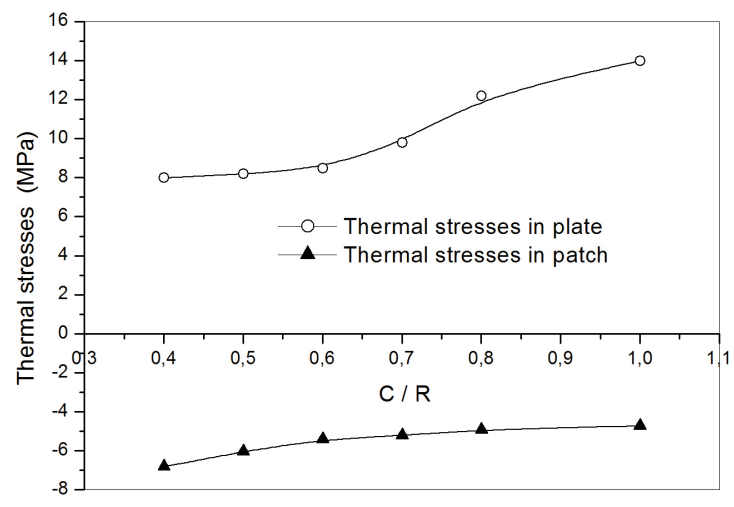

Figure 7. Variation of the mass gain according to the ratio $\mathrm{c} / \mathrm{R}$.

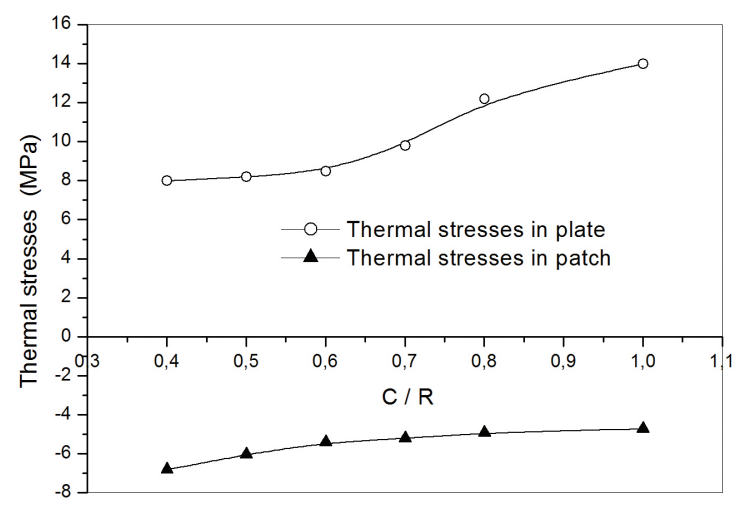

Figure 8. Maximal thermal stresses vs ratio $\mathrm{C} / \mathrm{R}$. 


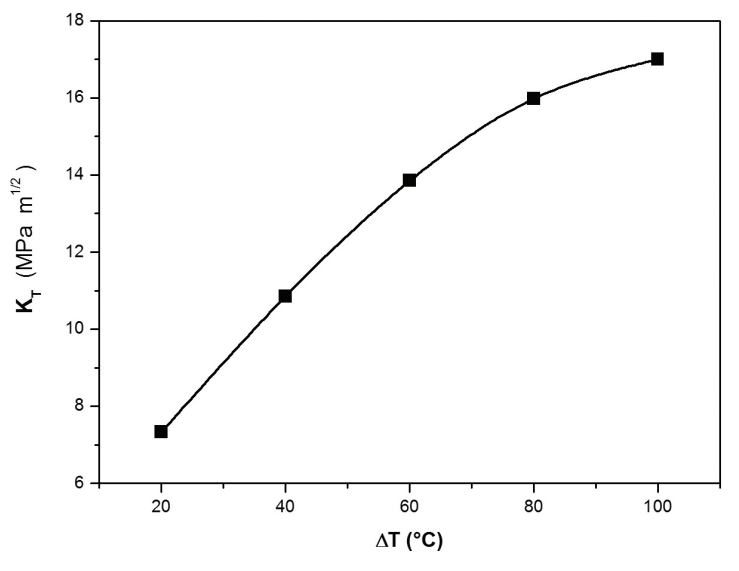

Figure 9. Thermal SIF vs temperature.

stresses in aluminum plate compared to the elliptical shape. And inversely the intensities if the thermal stresses in the patch are less significant for the circular shape.

In order to highlights the effect of the thermal residual stresses on the repair efficiency, the variation of thermal stress intensity factor (TSIF) is plotted in Figure 9 as a function of curing temperature for crack length $a=10 \mathrm{~mm}$ and for circular patch shapes. The thermal SIF increases with the temperature curing and this means that the thermal

\section{References}

1. Baker AA and Jones R. Bonded repair of aircraft structures. Dordrecht: Martinus Nijhoff; 1988. http://dx.doi. org/10.1007/978-94-009-2752-0.

2. Atluri SN. Structural integrity and durability. Forsyth: Tech Science Press; 1997.

3. Rose LRF. A cracked plate repaired by bonded reinforcement. International Journal of Fracture. 1982; 18(2):135-144. http:// dx.doi.org/10.1007/BF00019638.

4. Hart-Smith LJ. The design of repairable advanced composite structures. Long Beach: Douglas Aircraft Company; 1985.. http://dx.doi.org/10.4271/851830.

5. Chow WT and Atluri SN. Composite patch repairs of metal structures: adhesive nonlinearity, thermal cycling and debonding. AIAA Journal. 1997; 35(9):1528-1535. http:// dx.doi.org/10.2514/2.7481.

6. Lena MR, Klug JC and Sun CT. Composite patches as reinforcements and crack arrestors in aircraft structures. Journal of Aircraft. 1998; 35(2):318-323. http://dx.doi. org/10.2514/2.2302.

7. Baker AA and Chester RJ. Recent advances in bonded composite repair technology for metallic aircraft components. In: Proceeding of the international conference on advanced composite materials; 1993; Wollongong, Australia. Wollongong; 1993. p. 45-9.

8. Callinan RJ, Sanderson S and Keeley D. Finite element analysis of an F-111 lower wing skin fatigue crack repair. Melbourne: DSTO Aeronautical and Maritime Research Laboratory; 1997. $55 \mathrm{p}$.

9. Jones R and Chiu WK. Composite repairs to crack in thick metallic components. Composite Structures. 1999; 44(1):17-29. http://dx.doi.org/10.1016/S0263-8223(98)00108-1. residual stresses have a very negative effect on the repair efficiency. These stresses reduces the fatigue life of the repair structures. It is thus recommended to bond the patch repair without heating. Several structural adhesives can be used at room temperature.

\section{Concluding Remarks}

Our objective in this study is to compare the performances of semi-circular and semi-elliptical patches for repairing aircraft structures. The finite element method is used to achieve this objective. It was shown that the semi circular patch reduce significantly of the stress intensity factor at the crack tips what can improve the fatigue life of the repaired structures. In addition The reduction of the mass of the patch what can minimize the repair cost. The repair durability is improved by the semi-circular because this patch shape leads to weak adhesive stresses compared to the semi-elliptical shape. The thermal residual stresses are less significant in the circular patch shapes which can improve the repair efficiency.

\section{Acknowledgments}

The authors extends its appreciation to the Deanship of Scientific Research at King Saud University for funding the work through the research group No. RGP-VPP-035.

10. Chung KH and Yang WH. Fracture mechanics analysis of the bonded repair of skin/ stiener with an inclined central crack. Composite Structures. 2002; 55(3):269-276. http://dx.doi. org/10.1016/S0263-8223(01)00163-5.

11. Bachir Bouiadjra B, Achour T, Berrahou M, Ouinas D and Feaugas X. Numerical estimation of the mass gain between double symmetric and single bonded composite repairs in aircraft structures. Materials \& Design. 2010; 31(6):30733077. http://dx.doi.org/10.1016/j.matdes.2010.01.006.

12. Jones R and Callinan RJ. Finite element analysis of patched cracks. J Struct Mech. 1979; 7(2):107-130. http://dx.doi. org/10.1080/03601217908905315.

13. Jiann-Quo T and Kam-Lun S. Analysis of cracked plates with a bonded patch. Engineering Fracture Mechanics. 1991; 40(6):1055-1065. http://dx.doi.org/10.1016/00137944(91)90170-6.

14. Konsta-Gdoutos M, Gdoutos EE, Raftopoulos DD and Maissner J. Evaluation of stress intensity factors in metals by photoelastic coating and caustics. J Mech Behav Mater. 1996; 6(2):135-145. http://dx.doi.org/10.1515/JMBM.1996.6.2.135.

15. Bachir Bouiadjra B, Belhouari M and Serier B. Computation of the stress intensity factor for repaired cracks with bonded composite patch in mode I and mixed mode. Composite Structures. 2002; 56(4):401-406. http://dx.doi.org/10.1016/ S0263-8223(02)00023-5.

16. Haftka RT and Grandhi RV. Structural shape optimization-a survey. Computer Methods in Applied Mechanics and Engineering. 1986; 57(1):91-106. http://dx.doi. org/10.1016/0045-7825(86)90072-1.

17. Wieghardt K, Hartmann D and Leimbach KR. Interacting shape optimisation of continuum structures. Engineering Structures. 1997; 19(4):325-331. http://dx.doi.org/10.1016/ S0141-0296(96)00077-6. 
18. Brighenti R, Carpinteri A and Vantadori S. A genetic algorithm applied to optimisation of patch repairs for cracked plates. Computer Methods in Applied Mechanics and Engineering. 2006; 196(1-3):466-475. http://dx.doi. org/10.1016/j.cma.2006.07.004.

19. Heller M and Kaye R. Shape Optimisation for Bonded Repairs. In: Baker AA, Rose LRF, Jones R, editors. Advances in the Bonded Composite Repair of Metallic Aircraft Structure. Oxford: Elsevier; 2002. p. 269-315. http://dx.doi.org/10.1016/ B978-008042699-0/50012-7.

20. Kaddouri K, Ouinas D and Bachir Bouiadjra B. FE analysis of the behaviour of octagonal bonded composite repair in aircraft structures. Computational Materials Science. 2008; 43(4):11091111. http://dx.doi.org/10.1016/j.commatsci.2008.03.003.

21. Ouinas D, Bouiadjra BB, Serier B and Said Bekkouche M. Comparison of the effectiveness of boron/epoxy and graphite/ epoxy patches for repaired cracks emanating from a semicircular notch edge. Composite Structures. 2007; 80(4):514-522. http:// dx.doi.org/10.1016/j.compstruct.2006.07.005.

22. Ouinas D, Hebbar A, Bachir Bouiadjra B, Belhouari M and Serier B. Numerical analysis of the stress intensity factors for repaired cracks from a notch with bonded composite semicircular patch. Composites. Part B, Engineering. 2009; 40(8):804-810. http:// dx.doi.org/10.1016/j.compositesb.2009.06.002.

23. Deheeger A, Mathias JD and Grédiac M. A closed-form solution for the thermal stress distribution in rectangular metal/composites bonded joints. International Journal of Adhesion and Adhesives. 2009; 29(5):515-524. http://dx.doi. org/10.1016/j.ijadhadh.2008.10.004.

24. Aminallah L, Achour T, Bachir Bouiadjra B, Serier B, Amrouche A, Feaugas X, et al. Analysis of the distribution of thermal residual stresses in bonded composite repair of metallic aircraft structures. Computational Materials Science. 2009; 46(4):1023-1027. http://dx.doi.org/10.1016/j. commatsci.2009.05.008.

25. Wang CH, Rose LRF, Callinan R and Baker AA. Thermal stresses in plate with a circular reinforcement. International Journal of Solids and Structures. 2000; 37(33):4577-4599. http://dx.doi.org/10.1016/S0020-7683(99)00175-4.

26. Albedah A, Bachir Bouiadjra B, Aminallah L, Es-Saheb $\mathrm{M}$ and Benyahia F. Numerical analysis of the effect of thermal residual stresses on the performances of bonded composite repairs in aircraft structures. Composites. Part B, Engineering. 2011; 42(3):511-516. http://dx.doi.org/10.1016/j. compositesb.2010.11.013.

27. Mhamdia R, Bachir Bouadjra B, Serier B, Ouddad W, Feaugas $\mathrm{X}$ and Touzain S. Stress intensity factor for repaired crack with bonded composite patch under thermo-mechanical loading. Journal of Reinforced Plastics and Composites. 2011; 30(5):416-424. http://dx.doi.org/10.1177/0731684410397899.

28. Abaqus. Abaqus/CAE user's manual. Version 6.9. Pawtucket: Hibbitt, Karlsson \& Sorensen; 2007

29. Rybicki EF and Kanninen MF. A finite element calculation of stressintensity factors by a modified crack closure integral. Engineering Fracture Mechanics. 1977; 9(4):931-938. http:/ dx.doi.org/10.1016/0013-7944(77)90013-3.

30. Krueger R. The virtual crack closure technique: history, approach and applications. Hampton: ICASE; 2002.

31. Leski A. Implementation of the virtual crack closure technique in engineering FE calculations. Finite Elements in Analysis and Design. 2007; 43(3):261-268. http://dx.doi.org/10.1016/j. finel.2006.10.004. 